\title{
THE ROLE OF ORGANIZATIONAL EMOTIONS IN STRATEGIC LEADERSHIP: A LITERATURE REVIEW
}

\section{Sudirman *}

Doctoral Program in Management Science, University of Malang, Indonesia e-mail: sudirman.2004139@students.um.ac.id

*Correspondence: sudirman.2004139@students.um.ac.id

Submitted: 17 November 2021, Revised: 13 December 2021, Accepted: 14 December 2021

\begin{abstract}
Emotions are human things. When people consider emotions from a strategic leadership point of view, additional individual framing factors become unavoidable and play a role in an organization's management process. This research aimed to evaluate the existing literature on emotion and strategic leadership comprehensively. The study was a survey of the literature on emotion and strategic leadership. Because of the search and exclusion criteria applied, only 24 articles were relevant. The texts were studied using the grounded theory method to build a new theoretical model and identify essential characteristics of organizational emotion shifting. The model tried to demonstrate how the interaction of human and organizational elements and the task and problems faced by strategic leaders result in internal and external emotional shifts. This literature survey and theoretical integration provided a starting point for further research. The results show that the conceptualization of emotions in strategic leadership encompasses all five levels: positive emotions, negative emotions, emotional empowerment (internal emotion shaping), the establishment of external resources, and the use of power (external emotions shaping). The research revealed that emotion in organizational shaping was a key variable. This variable identified the numerous ways strategic leaders use emotion to shape organizations. It indicates that the concept can bring the person (strategic leader) and organizational levels together. In light of the limited literature, mainly focusing on strategic and emotional leadership, the model should be tested as a foundation for future research.
\end{abstract}

Keywords: emotions management; strategic leadership; emotion in the organization. 


\section{INTRODUCTION}

In leadership development, The objective of this research was to provide a comprehensive evaluation of the existing literature on emotion and strategic leadership. The study was a survey of the literature on emotion and strategic leadership. Because of the search and exclusion criteria applied, only 24 articles were relevant. The texts were studied using the grounded theory method to build a new theoretical model and identify essential characteristics of organizational emotion shifting. The model tried to demonstrate how the interaction of human and organizational elements and the task and problems faced by strategic leaders result in internal and external emotional shifts. This literature survey and theoretical integration provided a starting point for further research.

Strategic leaders must use their analytical skills to separate the pieces of a problem or scenario and synthesize longterm patterns in highly complex issues. (Bass, Laden, \& Burns, 2013) Executive activities were articulated in greater detail, focusing on holistic understanding, longterm organizational goals, and the organization's link to the environment. It was accomplished through expansion and reaching out to external stakeholders for agreement. The organization's main concern was acquiring and integrating resources. The top priorities were reduced uncertainty, increased stability and resources, and reduced competitiveness (Bass, 2007).

Aside from duty, an executive leader differs from other levels of leadership in that he or she has more power and position. Organizations, it was once thought, set formal and emotional rules for the organization (Fineman, 2016). The upper echelon theory argued this general rule, which suggested that organizations reflect executive managers' conditions and values. As a result of their special status and power, senior executives can easily influence organizations. However, the definitive study on the function of emotions in strategic leadership is rare, and no systematic evaluation has been conducted.

The goal of this study was to conduct a thorough review of the existing literature on emotion and strategic leadership. This study focused on strategic emotion and some parts of the broader topic of general leadership and emotion. Then came "emotions," one of the most frequently examined aspects of human life by experts (Lazarus, 1999). Because of the multiple extra individual framing aspects that undoubtedly play a role when examining emotions from a strategic leadership perspective is considerably larger.

Organizational emotion was a model that showed how the interaction of individual factors with multiple tasks challenged strategic leaders to lead the Shape of internal and external emotions in their leadership in an organization. This was the starting point of a potential field for exploring emotions and future challenges for strategic leaders. This was necessary because of the basic emotions that frame strategic leaders' ability to influence emotions in the organizations. 
According to several studies about leadership (Erez et al., 2008), (Avolio \& Gardner, 2005), strategic leadership was distinct from middle and lower-level leadership because of the types of organizational duties and responsibilities. Because senior leaders must go "beyond" the organization to observe things from a different perspective, their tasks were fundamentally different from those of lower-level executives (Poder, 2004); in comparison to lower-level executives who must look "within" a more comprehensive approach is taken (Klann, 2003).

Apart from responsibilities, an executive leader's difference compared to other leadership levels is increased power and status. Traditionally, organizations set formal rules and organizational emotional rules (Fineman, 2008). Upper echelon theory challenges this general rule and suggests that organizations reflect the conditions and values of executive managers. Their unique status and power make organizations easily influenced by the executive leaders who run them. However, research specific to the role of emotions in strategic leadership is sparse and has not been the subject of a comprehensive review.

\section{MATERIALS AND METHODS}

The search method was conducted in two steps to find the literature about emotions at higher leadership levels. The first: search the E-Journals database, google scholar. Different combinations were entered into the following search words: "leadership, executive, strategic, emotion." Each search included any descriptors or combinations (Akbar, 2020). Findings were limited to 2000-2020 to focus on the most recent findings.

In the second step, due to the large number of articles found during the search, the limitation was made to improve the quality of the findings. There were several exceptions for publications not written in English and unrelated to the research, such as the requirement that they focus on or apply to a higher level of leadership. For leadership, executive, emotion, there were 86 articles found, while for leadership, strategic, emotion, there were 50 . Due to a lack of relevance to the study, 112 articles were eliminated. As a result, 24 items met the requirements.

The technique of data analysis used literature review findings as data. Using the grounded theory (GTM) method, it was analyzed to make theory through data analysis (B. G. Glaser \& Holton, 2004). It means that other research papers in line with the research were used as data (B. Glaser \& Strauss, 2014).

\section{RESULTS AND DISCUSSION}

The analysis was conducted in two steps. Step 1: Articles were sorted using the constant comparative method (B. G. Glaser $\&$ Holton, 2004) into smaller and significant parts of information that were either descriptively labeled or coded. When new code was discovered, every data element was thoroughly compared and sorted into groups. This process yielded four distinct categories, including subcategories or subjects, as depicted in Table 1. 
Table 1. Empirical Research Findings on Emotion Management and Leadership Strategies which Thematically Categorized

\begin{tabular}{|c|c|c|}
\hline Category & Topic & Researcher \\
\hline $\begin{array}{l}\text { Emotion } \\
\text { Management }\end{array}$ & $\begin{array}{l}\text { Cultural Emotion } \\
\text { Capital Emotion }\end{array}$ & $\begin{array}{c}\text { (Fineman, 2016), } \\
\text { (Hochschild, 2015), (Huy \& } \\
\text { Shipilov, 2012) }\end{array}$ \\
\hline Leader Emotion & $\begin{array}{l}\text { Emotional Intelligence } \\
\text { Emotional contagion }\end{array}$ & $\begin{array}{c}\text { (George \& Dane, 2016), } \\
\text { (Whitman, Kraus \& Van } \\
\text { Rooy, 2014), (Kemper \& } \\
\text { Shaltout, 2011), (Bono \& } \\
\text { Yoon, 2012). }\end{array}$ \\
\hline $\begin{array}{l}\text { Tasks and Challenges } \\
\text { Strategic Leadership }\end{array}$ & $\begin{array}{l}\text { Tasks of Strategic Leadership } \\
\text { Challenges of strategic leadership }\end{array}$ & $\begin{array}{l}\text { (Bass, 2007), (Bass, Laden, \& } \\
\text { Burns, 2013). } \\
\text { (Avolio \& Yammarino, 2013), } \\
\text { (Poder, 2013), (Klann, 2015). }\end{array}$ \\
\hline $\begin{array}{l}\text { Emotion in } \\
\text { Organizational } \\
\text { Shaping }\end{array}$ & $\begin{array}{l}\text { Internal Emotional Shaping: } \\
\text { - Positive Emotion } \\
\text { - Negative Emotion } \\
\text { - Emotional empowerment } \\
\text { External Emotion Shaping: } \\
\text { - } \quad \text { Establishment of external } \\
\text { resources. } \\
\text { - } \quad \text { The use of power }\end{array}$ & $\begin{array}{l}\text { (Larsson et al., 2020), (Bass, } \\
\text { Laden, \& Burns, 2013), (Huy } \\
\text { \& Shipilov, 2012) } \\
\text { (Jones, 2016), (Lord \& Dinh, } \\
\text { 2014), (Stein \& Levine, 2013), } \\
\text { (Larsson et al., 2020) } \\
\text { (Klann, 2015), (Campbell et } \\
\text { al., 2017), (Nilsson et al., } \\
\text { 2011), (Fors Brandebo et al., } \\
\text { 2013), (Goleman et al., 2013). }\end{array}$ \\
\hline
\end{tabular}

Source: Data processed (2021)

Strategic leaders use emotion in various ways as an influencing tool to shape organizations. Step 2: Further comparison was conducted to find similarity, then it was combined into four categories. These four categories were made into a theoretical model by applying comparative analysis. According to (B. G. Glaser, 2002), a comparative analysis was used to make a theory, not to test it and find the relationships between data components when compiling categories.

\section{A. Emotion Management}

Leaders must be aware of emotional acceptance, which had been determined before by considering the context and history of an organization. The main points of previous research, which described several elements of emotion in different organizations, were framed by the use of emotions by strategic leaders in organizations. This superior category made the following 
identified supporting categories: cultural emotions and capital emotions.

(1) Cultural Emotion

There was a vibrant culture in a corporation. Each workplace had its language, habits, and meaning system, which included formal and informal norms concerning feelings that employees were allowed or not allowed to display (Fineman, 2016). These external variables shape the vibrant culture. Each business, in particular, has its emotional framework of permissible feelings.

Institutional emotional management began with establishing standards regarding how and what emotions should be displayed at work. It influenced people by projecting how they should think and feel at work. Every business has its own set of guidelines for expressing unique emotions, ranging from the most open to the most stringent (Hochschild, 2015). As a result, emotions communicate what is essential and required of the leader. Individuals are supposed to deconstruct emotions using their understanding of the social context in the emotional method. The emotional expression of strategic leaders can be shaped as the foundation for building an organization's cultural feelings using this notion.

(2) Capital Emotions

The accumulated feeling of positive intention toward the company and how it runs is capital emotion in organizations (Huy \& Shipilov, 2012). They describe how emotions may be leveraged as a type of organizational capital by building assets in employees that can be used to invest other resources in the hopes of a future return. In order to gain access to resources such as support and information, organizations can instill feelings of goodwill or pleasant emotions in their employees.

Authenticity, pride, attachment, and enjoyment are four crucial components in generating emotional capital, according to (Huy \& Shipilov, 2012). As a result, strategic leaders who employ positive emotions to develop capital emotions are critical to the strategy's success.

B. Leaders' Emotion

Strategic leaders' fundamental emotional skills level was one of the critical variables in their ability to affect emotions. The data analysis defined the fundamental emotional talents that framed strategic leaders' ability to affect emotions in organizations. Emotional intelligence and emotional contagion were used to create this higher category.

(1) Emotional Intelligence

This review appears as yet another emotional skill in four separate leadership sources, each with a define descriptions. Emotional intelligence was defined in the article as a set of verbal and nonverbal abilities that enable a person to generate, recognize, express, comprehend, and assess their own and others' emotions to guide cognition and action in order to cope with demands and pressures around them successfully ((Whitman, Kraus \& Van Rooy, 2014). It 
can be recognized as an "inter-person" trait according to (Ashkanasy \& Jordan, 2008) level 5-level model (level 2).

Emotional intelligence includes evaluating and expressing emotions (George \& Dane, 2016). It is critical to accurately predict emotions since emotional input is used to make decisions. People's ability to meet their requirements and execute essential duties depends on their ability to articulate their emotions accurately.

(2) Emotional Contagion

Emotional contagion refers to the ability to notice and feel emotions or similar behaviors in others (Kemper \& Shaltout, 2011). This is a natural reaction that is frequently visible in overt conduct. Leaders' emotions are supposedly linked to their followers' feelings through emotional contagion, both positively and adversely. Employees can be inspired and motivated by their leaders' positive emotional responses on an individual and group level. On the other hand, distressed leaders are more likely to share their feelings with their followers (Bono \& Yoon, 2012). The ability of a leader to recognize and communicate their emotions is critical for properly managing the emotions of their followers.

C. Tasks and Challenges Strategic Leaders

The tasks and challenges faced by top leaders or executives differ from those faced by mid-level and lower-level leaders.

(1) Task Strategic Leaders
Many descriptions summarized and explained the tasks faced by strategic leaders in their job descriptions. The duty compilation of senior executive Bass (2007) includes long-term planning and high-quality cognitive mapping of the organization and its environment, range of activity boundaries, network development, and consensus-building. Leadership factors describing organizational improvement through transformational leadership were also included as they were often described as valid at the executive level. The majority involve aspects of behavior related to others, including using the leader's emotional framing factors (Bass, Laden, \& Burns, 2013).

However, cognitive responsibilities such as long-term planning or cognitive mapping require further investigation to determine the relationship between emotional framing factors. They entail the responsibility for making major organizational decisions that significantly impact one's life. When a firm, for example, needs to downsize for the benefit or survival of the company, senior leaders do long-term analysis and planning that impacts individual lives. An executive leader's job description includes this type of emotional problem.

(2) The Challenge of Strategic Leaders

The most common challenges to strategic leaders were focused on organizational change, responding to physical and emotional crises, and the 
gap between executive leaders and their subordinates. Organizational change is frequently accompanied by disagreement and the leader's fear of losing face, necessitating emotional management on the part of the leader (Poder, 2013). Certain social positions in society once provided individuals with contextually independent authority, but this is no longer the case. On the other hand, individuals might develop power by acting on their feelings. As a result, power can be felt as an emotion when employed for a change.

Emotion in leadership was challenged when leaders must respond to a crisis as he surrounded by an unstable emotional environment. Communication, clarity of vision and principles, and caring are three critical strategies leaders can employ to improve results in crises (Klann, 2015). Despite the many obstacles that strategic leadership faced, one key topic related to emotion was the physical and emotional gap between leaders and subordinates.

The distance was one of the most significant challenges executive leaders face (Avolio \& Yammarino, 2013). The physical distance of the leader hurt organizational commitment. It showed that strategic leaders who face structural and physical distance from their workforce must alter their leadership to overcome these barriers. A leader who fails to elicit his subordinates' intrinsic values or provide an inspirational vision cannot anticipate high levels of involvement or unity from his followers.

D. Emotion in Organizational Shaping

Strategic leaders employed emotions to change their subordinates' behaviors to complete internal and external organizational tasks and obstacles. Internal organizational emotions Shaping and external organizational emotions Shaping are two issues covered in this area.

(1) Internal Organizational Emotions Shaping

This category includes topics related to the strategic leader's ability to shape the internal emotional environment by using his power to influence the organization. In Shape the internal organizational emotions, leaders optimize positive emotions, minimize negative emotions and empower emotions to achieve organizational goals

a. Positive Emotion

Leaders' employment of positive emotions impacted their organizations due to a combination of emotional elements and the development of emotional management aspects in strategic leadership. Even if the divide is still a concern, challenges occur in how leaders can communicate cultural sentiments to lower levels of the business. According to the statistics, it can be accomplished in two ways: directly or indirectly. Executive leaders can immediately develop capital emotionally with their subordinates (Huy \& Shipilov, 2012). Another option is for the leader to employ the indirect 
Shape, which involves assigning associate leaders to lower hierarchical organizational chains (Larsson et al., 2020). It primarily relied on the leader's image, which he cultivated by exemplary behavior.

Charismatic and transformational leadership styles are two leadership theories that involve using positive emotions to encourage and inspire followers. Charismatic leadership positively impacts subordinates' happiness emotions (Larsson et al., 2020). (Erez et al., 2008) The leader's rhetorical talent and personal ability to attract and relate to others were essential for charismatic leadership. According to (Erez et al., 2008), this attribute encourages subordinates to follow the leader's vision since it fosters identification with the leader and, as a result, internalization of the vision.

Transformational leadership and authentic leadership were closely associated (Avolio \& Yammarino, 2013); transformational leadership was a leadership theory that incorporated many aspects of subordinates' emotions. According to (Bass, Laden, \& Burns, 2013), transformational leadership is characterized by the concept of charisma, or the ability of leaders to elicit emotions in their subordinates through their own emotions. To summarize, the leader's emotional and organizational framing factors were critical in motivating subordinates to complete the organization's internal responsibilities. This topic has been examined in several contemporary leadership theories.

b. Negative Emotion

Overloading emotions was an experience where people were in a bad emotional situation, making them unable to think effectively (Jones, 2016). Classic stress and anxiety symptoms such as tightness, unpleasant facial expressions, perspiration, and fast breathing were described. These physiological symptoms and impaired cognitive function naturally have a catastrophic effect in a crisis. It presented a challenge for strategic leaders to proactively and reactively deal with overload emotions in crisis for themselves and their associate leaders.

There were numerous approaches to reducing negative feelings. Through diversionary methods, neutralizing was thought to prevent the appearance of undesirable emotions (Lord \& Dinh, 2014). Emotions were employed to sum up, or distinguish possibly distressing emotions from behaviors that were deemed inappropriate. Humor, for example, can be used to normalize the experience of something disturbing into a more acceptable frame of reference. Several research claimed that utilizing this method in crises resulted in emotional decline (Stein \& Levine, 2013) and (Larsson et al., 2020). In crises, people must remain cool or maintain a safe distance from their work to maintain professionalism in their work and tasks. Leaders at the highest levels involved in crisis circumstances showed relatively little emotion (Silverstein et al., 2008) and (Larsson et al., 2020). This was 
attributable to organizationally established emotional regimes, such as informal expectations about emotional expression from the hierarchy's top leaders who used emotion management tactics.

In addition, a person's anxiety level can interfere with their tasks (Stein \& Levine, 2013). Stein stated that realistic anxiety awareness during critical periods helps handle acute situations. In other words, the situation needs to be normalized but not underestimated or even exaggerated to be worse than the actual condition. Many theoretical and empirical contributions discussed the function of managing negative emotions during a crisis to perform an important task. However, only a littlediscussed how to handle the emotional downturn in an organization. There was no discussion of the role of positive emotions in critical situations. There was no leadership theory identified, such as the minimization aspect of negative emotion

\section{c. Emotion Empowerment}

Strategic leaders must delegate power and authority to frontline leaders in crisis scenarios due to dynamic conditions (Fors Brandebo et al., 2013) (Fors Brandebo, Sjöberg, Larsson, Eid, \& Kjellevold Olsen, 2013). The need to delegate the power was spotted the importance of trust. When high-level military commanders responded to crisis circumstances, this was common. Considering the organizational gap, change, or crisis in strategic leadership, emotional support was necessary offered to associate leaders.

Several studies distinguish lead in crisis versus everyday situations by explaining the need for increased emotional support (Klann, 2015). Leaders who will be confronted with complex events that will test their moral character (Campbell et al., 2017) must believe in their ability to address and resolve moral challenges. In these stressful conditions, leaders' decisions would boost or lessen their influence over their subordinates. In crises, emotionally supportive leaders can create a safer environment by increasing moral sensitivity and awareness (Nilsson et al., 2011). The importance of the leader's role was to be emotionally engaging and ensure and provide clarity during the threat or uncertainty (Goleman et al., 2013).

(2) Internal Organizational Emotions Shaping

This category identified two things that describe executive leaders' emotional influence, which is used to fulfill external organizational tasks and challenges, called the establishment of external resources and the use of power.

a. Establishment of External Resources.

The majority of external actions were centered on networking and looking for negotiation and organizational expansion opportunities. Contextual intelligence is demonstrated by a leader's ability to comprehend the changing environment and capitalize on trends (Kutz \& Bamford-Wade, 2014). It required a leader's analytical skills to 
match resources to relevant organizational needs and work with rather than against the tide of change. $A$ 'borderline' characterizes the activities that an individual engages in to improve the efficiency of their organization in the external world, particularly during times of crisis when a person is often reliant on their surroundings and when jobs are more complex (Larsson et al., 2020) and (Nilsson et al., 2011). Their theoretical model for leader-wide range activities showed that emotional fluency and trust development were essential features. According to the conclusions of this study, the most crucial feature of network collaboration is establishing trust among the various parties involved.

b. The Use of Power

The ability of a leader to use his or her moral beliefs, or the ideals and vision that he or she wishes to impart, to gain followers is known as the use of power. This type of power seemed attractive because it relies on emotional influence to lead others to pursue the same goal. This type of power is often associated with politics and top-level leadership (Mahdi \& Almsafir, 2014). Senior executives to exploit opportunities in the long-term development and planning of the organization can view external organizational emotion shifting as a power play.

\section{CONCLUSIONS}

Multiple previous investigations were categorized into four categories in this literature collection utilizing constant comparisons in the grounded theory technique. Analyses were created by merging categories and topics into a causal model, following methodological principles specified by the authors. The research revealed that emotion in organizational shaping was a key variable. This variable identified the numerous ways strategic leaders use emotion to shape organizations. When the model was compared to the 5 -level model of emotions in organizations proposed, it was discovered that the conceptualization of emotions in strategic leadership encompasses all five levels: positive emotions, negative emotions, emotional empowerment (internal emotion shaping), the establishment of external resources, and the use of power (external emotions Shaping). It indicates that the concept can be viewed to bring the person (strategic leader) and organizational levels together. In light of the limited literature, mainly focusing on strategic and emotional leadership, the model should be tested as a foundation for future research.

\section{REFERENCES}

Akbar, Y. R. (2020). Analisis Kuantitatif: Pengolahan Data Statistik Menggunakan SPSS \& Pengumpulan Data Survei Google Form/Survey Monkey (Vol. 1). Pena Persada.

Ashkanasy, N. M., \& Jordan, P. J. (2008). A Multi-Level View of Leadership and Emotion. Affect and Emotion: New Directions in Management Theory and Research, 17-39.

Avolio, B. J., \& Gardner, W. L. (2005). 
Authentic Leadership Development: Getting to the Root of Positive Forms of Leadership. The Leadership Quarterly, 16(3), 315-338.

Bass, B. M. (2007). Executive and Strategic Leadership. International Journal of Business, 12(1).

Bass, B. M., \& Bass, R. (2009). The Bass Handbook of Leadership: Theory, research, and managerial applications. Simon and Schuster.

Bono, J. E., \& Ilies, R. (2006). Charisma, Positive Emotions, and Mood Contagion. The Leadership Quarterly, 17(4), 317-334.

Campbell, D. J., Hannah, S. T., \& Matthews, M. D. (2010). Leadership In Military and Other Dangerous Contexts: Introduction to The Special Topic Issue. Military Psychology, 22(sup1), S1-S14.

Erez, A., Misangyi, V. F., Johnson, D. E., LePine, M. A., \& Halverson, K. C. (2008). Stirring The Hearts Of Followers: Charismatic Leadership As The Transferal Of effect. Journal of Applied Psychology, 93(3), 602.

Fineman, S. (2008). Introducing The Emotional Organization. The Emotional Organization: Passions and Power, 1-11.

Fors Brandebo, M., Sjöberg, M., Larsson, G., Eid, J., \& Kjellevold Olsen, O. (2013). Trust In A Military Context: What Contributes To Trust in Superior And Subordinate Leaders? Journal of Trust Research, 3(2), 125-145.

George, J. M. (2000). Emotions and Leadership: The Role of Emotional Intelligence. Human Relations, 53(8),
1027-1055.

Glaser, B. G. (2002). Conceptualization: On Theory and Theorizing Using Grounded Theory. International Journal of Qualitative Methods, 1(2), 23-38.

Glaser, B. G., \& Holton, J. (2004). Remodeling Grounded Theory. Forum Qualitative Sozialforschung/Forum: Qualitative Social Research, 5(2).

Glaser, B., \& Strauss, A. (2014). Applying Grounded Theory. The Grounded Theory Review, 13(1), 46-50.

Goleman, D., Boyatzis, R. E., \& McKee, A. (2013). Primal Leadership: Unleashing The Power of Emotional Intelligence. Harvard Business Press.

Hochschild, A. R. (2009). Invited Commentary: Can Emotional Labour Be Fun? International Journal of Work Organisation and Emotion, 3(2), 112119.

Huy, Q., \& Shipilov, A. (2012). The Key To Social Media Success Within Organizations. MIT Sloan Management Review, 54(1), 73.

Jones, T. S., \& Bodtker, A. (2001). Mediating With Heart in Mind: Addressing Emotion in Mediation Practice. Negotiation Journal, 17(3), 217-244.

Kemper, K. J., \& Shaltout, H. A. (2011). NonVerbal Communication of Compassion: Measuring Psychophysiologic Effects. BMC Complementary and Alternative Medicine, 11(1), 1-9.

Klann, G. (2003). Character Study: Strengthening The Heart of Good Leadership. Leadership in Action: A 
Publication of the Center for Creative Leadership and Jossey-Bass, 23(3), 3-7.

Kutz, M. R., \& Bamford-Wade, A. (2014). Contextual Intelligence: A Critical Competency for Leading. Approaches to Managing Organizational Diversity and Innovation, 42.

Larsson, G., Sjöberg, M., Nilsson, S., Alvinius, A., \& Bakken, B. (2007). Indirect Leadership: A Quantitative Test of A Qualitatively Developed Model. Leadership \& Organization Development Journal.

Lazarus, R. S. (1999). Lazarus, R. S. (1999). Stress and Emotion: A New Synthesis. New York: Springer Publishing Company. New York. Springer Publishing Company. Revised May 4, 2006.

Lord, R. G., \& Harvey, J. L. (2002). An Information Processing Framework for Emotional Regulation. Emotions in The Workplace: Understanding the Structure and Role of Emotions in Organizational Behavior, 115-146.

Mahdi, O. R., \& Almsafir, M. K. (2014). The Role of Strategic Leadership in Building Sustainable Competitive Advantage in The Academic Environment. Procedia-Social and Behavioral Sciences, 129, 289-296.

Nilsson, S., Sjöberg, M., Kallenberg, K., \& Larsson, G. (2011). Moral Stress in International Humanitarian Aid and Rescue Operations: A Grounded Theory Study. Ethics \& Behavior, 21(1), 49-68.

Poder, P. (2004). Feelings of Power and the Power of Feeling. Handling Emotion In.

Silverstein, A., Silverstein, V. B., \& Nunn, L.
S. (2008). Adaptation. Twenty-First Century Books.

Stein, M. (2004). The Critical Period of Disasters: Insights From SenseMaking and Psychoanalytic Theory. Human Relations, 57(10), 1243-1261.

Van Rooy, D. L., \& Viswesvaran, C. (2004). Emotional intelligence: A MetaAnalytic Investigation of Predictive Validity and Nomological Net. Journal of Vocational Behavior, 65(1), 71-95. under the Creative Commons Attribution (CC BY SA) license (https://creativecommons.org/licenses/by$\mathrm{sa} / 4.0 /)$. 